\title{
Is Clostridium difficile infection still a problem for hospitals?
}

\author{
David A. Enoch MBBS MSc, Sani H. Aliyu MBBS MSc
}

See related research article by Forster and colleagues on page 37 and at www.cmaj.ca/lookup/doi/10.1503/cmaj.110543

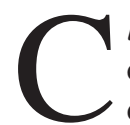

lostridium difficile is the most common cause of hospital-acquired infectious diarrhea in the developed world and has re-emerged in recent years with apparent greater morbidity and mortality, ${ }^{1}$ partly due to the appearance of a hypervirulent strain of the bacterium, North American pulsed-field type 1 NAP1/PCR ribotype 027. This strain has now been detected in Canada, the United States, several European countries and Australia.

Not surprisingly, the related CMAJ article by Forster and colleagues shows that hospitalacquired infection with $C$. difficile is associated with an increased length of stay. ${ }^{2}$ The authors considered the time-varying nature of infection with $C$. difficile and patients' baseline risk of death at admission, thus resulting in a shorter length of stay in hospital than previously reported. ${ }^{3}$

Clostridium difficile is transmitted via the fecal-oral route, although evidence of airborne spread is emerging. ${ }^{4}$ Although $C$. difficile can be cultured from the stool of healthy adults, most people remain asymptomatic. Disruption of the gut flora, typically by antibiotics, allows $C$. difficile to proliferate, thus resulting in infection.

The incidence of infection with $C$. difficile has fallen in recent years in several countries, including England (Appendix 1, available at www.cmaj.ca/lookup/suppl/doi:10.1503/cmaj $.111449 /$-/DC1), ${ }^{5}$ with a corresponding fall in mortality. However, infection with $C$. difficile remains a major problem for hospitals. This commentary highlights the key strategies for the prevention and management of $C$. difficile.

Preventive measures are required to reduce both acquisition of $C$. difficile and infection in people colonized by the organism. A "care bundle" approach has worked to reduce the number of cases in both Canada ${ }^{6}$ and the United Kingdom. ${ }^{7}$ Evidence-based national guidelines demand that all elements of the bundle be adhered to at all times. ${ }^{8}$ These elements include prudent prescribing of antibiotic medications, proper hand hygiene, use of personal protective equipment, early isolation of patients who have been colo- nized or infected and environmental cleaning.

Several studies have classified antibiotic agents into high- and low-risk categories (Appendix 2, available at www.cmaj.ca/lookup /suppl/doi:10.1503/cmaj.111449/-/DC1). ${ }^{9}$ However, any antibiotic may predispose a patient to infection with $C$. difficile. It is therefore important to implement guidelines for antibiotic stewardship. ${ }^{8}$ Any antibiotic prescribed should adhere to local guidelines for treatment and prophylaxis (based on local susceptibility profiles), and broadspectrum agents should be avoided. The indication should be documented along with a date on which treatment should stop or be reviewed. The shortest treatment course likely to be effective should be prescribed, and prescriptions should be reviewed daily to assess need and to ensure the antibiotic with the narrowest spectrum is being used. Where possible, single doses of antibiotic agents should be used for surgical prophylaxis.

Soap and water are more effective than alcoholbased sanitizers for eliminating $C$. difficile spores. Washing one's hands before and after contact with patients suspected or confirmed to have an infection with $C$. difficile is essential, as is wearing personal protective equipment when caring for patients and handling clinical specimens. ${ }^{8}$ The early isolation of patients with diarrhea is necessary to reduce airborne spread and environmental contamination. ${ }^{4}$

Environmental decontamination using chlorinecontaining compounds $(\geq 1000$ ppm available chlorine) is more effective than using detergent

\section{KEY POINTS}

- Infection with Clostridium difficile is the most common cause of hospital-acquired diarrhea in the developed world.

- Prudent prescribing of antibiotics, correct hand hygiene, the use of personal protective equipment, environmental decontamination and isolation or cohort nursing may prevent infection.

- National and local surveillance of infections should guide the implementation of control measures.

- Infection with C. difficile is treated with oral vancomycin or metronidazole, according to the severity of disease; treatment should be escalated if no response is seen. 
alone. ${ }^{8}$ In addition, hydrogen peroxide as a dry mist or vapour is emerging as an effective alternative for reducing environmental contamination. ${ }^{10}$

The Department of Health in England instituted mandatory surveillance of infections with C. difficile in 2004. National legislation (the Health Act 2006) introduced a statutory code of practice for infection control, ${ }^{11}$ and targets were set in 2008 to reduce infections by $30 \%$ by 2010 2011. ${ }^{12}$ These targets were largely met, possibly because hospital managers were held personally accountable for ensuring the measures were implemented. The reporting of cases of $C$. difficile is now mandatory in a number of American states and four Canadian provinces, but no national datasets exist. ${ }^{13,14}$ The US has subsequently set a target to reduce the onset of cases in health care facilities by $30 \%$ before $2013 .^{1.5}$

Recurrence of disease may represent reinfection or relapse. A meta-analysis of 12 studies involving 1382 patients with $C$. difficile infection found that continued use of the causative antibiotic agent(s) after diagnosis, the use of antacid medication and older age were all significantly associated with increased risk of recurrence..$^{16} \mathrm{An}$ injection of human monoclonal antibodies against C. difficile toxins $\mathrm{A}$ and $\mathrm{B}$ has been shown to reduce recurrences. ${ }^{17}$

Metronidazole remains the treatment of choice for mild to moderate infection with $C$. difficile, ${ }^{8}$ but oral or rectal vancomycin is more effective for severe cases (raised white blood cell count, acutely rising serum creatinine level, temperature $>38.5^{\circ} \mathrm{C}$ or severe colitis). ${ }^{18}$ Treatment of recurring infections and the roles of surgery and intravenous immunoglobulins have been discussed elsewhere. ${ }^{8}$

Fidaxomicin (200 mg twice daily) was equivalent to vancomycin (125 mg four times daily) in a randomized controlled trial involving patients with acute infection with $C$. difficile. Fidaxomicin was associated with a significantly lower rate of recurring infection. ${ }^{19}$

Adhering to basic evidence-based precautions can rapidly reduce the transmission of $C$. difficile and its associated mortality. Surveillance is essential to assess the efficacy of interventions. Such measures appear to have reduced the rates of infection in the UK, possibly because of increased management and clinical responsibility.

\section{References}

1. Karas JA, Enoch DA, Aliyu SH. A review of mortality due to Clostridium difficile infection. J Infect 2010;61:1-8.

2. Forster AJ, Taljaard M, Oake N, et al. The effect of hospitalacquired infection with Clostridium difficile on length of stay in hospital. CMAJ 2012;184:37-42.
3. Pepin J, Valiquette L, Cossette B. Mortality attributable to nosocomial Clostridium difficile associated disease during an epidemic caused by a hypervirulent strain in Quebec. CMAJ 2005; 172:1037-42

4. Best EL, Fawley WN, Parnell P, et al. The potential for airborne dispersal of Clostridium difficile from symptomatic patients. Clin Infect Dis 2010;50:1450-7.

5. Quarterly counts of $C$. difficile for patients aged 2 years and over (April 2007-March2011). London (UK): Health Protection Agency; 2011. Available: www.hpa.org.uk/web/HPAwebFile /HPAweb C/1278944233852 (accessed 2011 Aug. 12).

6. Muto CA, Blank MK, Marsh JW, et al. Control of an outbreak of infection with the hypervirulent Clostridium difficile $\mathrm{BI}$ strain in a university hospital using a comprehensive "bundle" approach. Clin Infect Dis 2007;45:1266-73.

7. High impact intervention: care bundle to reduce the risk from Clostridium difficile. London (UK): Department of Health; 2007. Available: http://hcai.dh.gov.uk/files/2011/03/Document _Clostridium_difficile_Infection_High_Impact_Intervention FINAL 101210.pdf (accessed 2011 Aug. 12).

8. Cohen SH, Gerding DN, Johnson S. Clinical practice guidelines for Clostridium difficile infection in adults: 2010 update by the Society for Healthcare Epidemiology of America (SHEA) and the Infectious Diseases Society of America (IDSA). Infect Control Hosp Epidemiol 2010;31:431-55.

9. Bignardi GE. Risk factors for Clostridium difficile infection. J Hosp Infect 1998;40:1-15.

10. Shapey S, Machin K, Levi K, et al. Activity of a dry mist hydrogen peroxide system against environmental Clostridium difficile contamination in elderly care wards. J Hosp Infect 2008;70:136-41.

11. Health Act 2006. Code of practice for the preventio and control of healthcare associated infections. London (UK): Department of Health; 2006.

12. National target to reduce Clostridium difficile infections: SHA envelopes - Reissue. London (UK): Department of Health; 2008. Available: www.dh.gov.uk/en/Publicationsandstatistics/Letters andcirculars/Dearcolleagueletters/DH_082702 (accessed 2011 Nov. 6).

13. Silversides A. Ontario's hospitals surpass those of Quebec in $C$. difficile rates. CMAJ 2008;178:1649.

14. State-based HAI prevention activities. Atlanta (GA): The Centers for Disease Control and Prevention; 2011. Available: www .cdc.gov/HAI/stateplans/HAIstatePlans-map.html (accessed 2011 Nov. 6).

15. Progress toward eliminating healthcare-associated infections: Meeting report summary; 2010 Sept. 23-24; Arlington (VA), Atlanta (GA): Centers for Disease Control and Prevention, Division of Healthcare Quality Promotion. Available: www.hhs.gov /ash/initiatives/hai/actionplan/cdc_c_diff.pdf (accessed 2011 Aug. 12).

16. Garey KW, Sethi S, Yadav Y, et al. Meta-analysis to assess risk factors for recurrent Clostridium difficile infection. J Hosp Infect 2008;70:298-304

17. Lowy I, Molrine DC, Leav BA, et al. Treatment with monoclonal antibodies against Clostridium difficile toxins. $N$ Engl J Med 2010;362:197-205.

18. Zar FA, Bakkanagari SR, Moorthi KM, et al. A comparison of vancomycin and metronidazole for the treatment of Clostridium difficile-associated diarrhoea, stratified by disease severity. Clin Infect Dis 2007;45:302-7.

19. Louie TJ, Miller MA, Mullane KM, et al.; OPT-80-003 Clinical Study Group. Fidaxomicin versus vancomycin for Clostridium difficile infection. N Engl J Med 2011;364:422-31.

Affiliations: David Enoch is with the Department of Clinical Microbiology and Public Health Laboratory, Peterborough and Stamford Hospitals, National Health Service Foundation Trust, Peterborough City Hospital, Bretton Gate, Peterborough, UK; and Sani Aliyu is with the Department of Clinical Microbiology and Public Health Laboratory, Health Protection Agency, Addenbrooke's Hospital, Cambridge, UK.

Contributors: Sani Aliyu and David Enoch both provided substantial contributions to the conception and design of the paper. David Enoch drafted the article and Sani Aliyu offered major revisions. Both authors approved the final version submitted for publication. 